\title{
Non-specific Factors that may Influence Significance of Urinary Steroid Excretion in Breast Cancer
}

\author{
J. A. DURANT H. MILLER
}

British Medical Journal, 1973, 4, 767-770

\section{Summary}

The urinary excretion of corticosteroids (17-oxogenic steroids) and adrenal androgens (11-deoxy-17-oxosteroids) was studied in women below the age of 50 in a variety of clinical situations for comparison with a normal group. The conditions studied were: chronic debility from non-malignant disease, weight reduction, admission to hospital and surgery for varicose veins, hepatic non-malignant disease, and non-mammary cancer.

The objective of the study was to determine whether the changes found in early and advanced breast cancer and used to judge the prognosis of the disease are specific to the disease or are merely incidental to the degree of illness caused by the disease.

Similar changes to those found in breast cancer-principally a reduction in the excretion of the androgens-were found in the women with severe hepatic disease and in advanced non-mammary cancer. These were also found to follow the effects of severe surgical stress.

It is concluded that the changes found in breast cancer are a measure of the general systemic disturbance caused by the disease and are not due specifically to it. Nevertheless, the value of their prognostic significance remains unchallenged.

\section{Introduction}

After the recognition that hormone therapy or endocrine organ ablation could modify the course of malignant tumours arising in certain endocrine target tissues-notably the breast and the prostate-it was a short step to the optimistic suggestion that, just as in experimental animals, cancers in these human situations arose as a consequence of an abnormal hormonal environment.

Indeed, in the first report of the Imperial Cancer Research Fund's Guernsey Breast Cancer Trial (Bulbrook and Hayward, 1967) it was claimed that in a population of ostensibly healthy women aged between 35 and 55 years it was possible to identify a group of women ( $20 \%$ of those studied) whose chances of developing breast cancer was 2.35 times greater than that of the whole population from which they were derived.

This trial, which is still in progress, was initiated after the partially successful attempts to predict the outcome of hormonal surgery in women with advanced breast cancer by preoperative "discriminant function" calculations derived from urinary steroid measurements (Bulbrook et al., 1960; Miller et al., 1967; Thomas et al., 1967) and the finding (Bulbrook et al., 1962) that some women with early breast cancer had abnormal steroid excretion.

Portsmouth and Isle of Wight Area Pathology Service, Central Laboratory, St. Mary's General Hospital, Portsmouth PO3 6AG J. A. DURANT, M.sC., PH.D., Top Grade Biochemist H. MILLER, F.R.C.P., F.R.C.PATH., Senior Pathologist
This paper is concerned with the effects on urinary steroid excretion of a number of factors that may be expected to occur in women with advanced breast cancer as a result of the general illness accompanying the disease, and not due particularly to the nature of the disease itself. It was felt that such a study would shed light on the original premises which led to the Guernsey trial. Nabarro (1960) had been swift to comment that the original discriminant function was a reflection of the severity of the general illness rather than an indicator of hormonal environment specifically associated with the disease.

The factors chosen for study were: (a) the general conditions of debility and of loss of weight, since these are associated with all forms of progressive disease; $(b)$ the results of admissions to hospital and of subsequent acute surgical stress; (c) the presence of hepatic disease (hepatic metastases, are a common mode of spread of breast cancer and the liver is the major area of steroid hormone metabolism; and $(d)$ the presence of early and advanced cancer in sites other than the breast.

\section{Patients}

All the women studied were below 50 years of age. We have shown (Miller and Durant, 1968) that the "alternative discriminating function" (Miller et al., 1967) is rarely negative in healthy women below this age, whereas older women are just as likely to have negative discriminants whether they are healthy or whether they suffer from localized or advanced breast cancer. None of the women were taking any form of hormone preparation, whether oral contraceptive steroids or otherwise.

\section{NORMAL GROUP}

The 48 women studied were a different group to those reported on previously (Miller et al., 1967; Miller and Durant, 1968).

\section{CHRONIC DEBILITY}

There were 14 women in this group. They were all severely physically handicapped and in the advanced non-remitting stages of their disease. Four had multiple sclerosis, three had muscular dystrophy, two had rheumatoid arthritis, and there were single cases of ulcerative colitis, hypertensive heart disease, respiratory poliomyelitis, syringomyelia, and pulmonary sarcoidosis.

\section{WEIGHT LOSS}

Ten healthy women attending a "weight watchers" course, weighing initially between 90 and $65 \mathrm{~kg}$, were studied during their attempt to lose weight by dietary means and exercise. Seven lost between 10 and $2 \mathrm{~kg}$ in one month, the other three gained between 2 and $6 \mathrm{~kg}$. Urine samples were collected at the beginning of the course and one month later. 
ADMISSION TO HOSPITAL AND SURGICAL STRESS

Urine samples were collected from 20 otherwise healthy women on the day of their admission to hospital for varicose vein ligation and on the first and second days after operation.

\section{HE?ATIC DISEASE}

Thirty-three women were studied. Of these 26 had acute infective hepatitis, four had obstructive jaundice due to cholelithiasis, two had cholecystitis, and one had alcoholic cirrhosis. All but the latter three were jaundiced when first seen. Of those with hepatitis 22 provided two urine samples and eight gave three samples as the disease showed signs of improvement. The second samples were collected after the jaundice had disappeared but when results of liver function tests were still abnormal. The third samples were collected when the liver function had returned to normal.

\section{NON-MAMMARY CANCER}

Apart from the breast and corpus uteri, epithelial cancer is rare in the age group under study, and many of those with lymphomata who might have been asked to take part were on hormone therapy. However, 37 subjects were selected. Thirteen had cancer of the cervix uteri, of whom two had metastatic spread, eight had Hodgkin's disease, three had an inoperable bronchial carcinoma, and the remainder had various sarcomata.

The latter two groups were divided into two categories of assessed ill health: a "mildly ill" class who were ambulant, non-febrile, only minimally affected by their disease, and who had not lost weight; and an "ill" class who were confined to bed, were febrile, or had suffered significant loss of weight, and were causing immediate concern to their doctor. These categories were based on the clinical judgement of their doctors after discussion with the authors.

None of the patients were receiving hormone therapy and none had evidence of endocrine gland involvement. All were volunteers after the project had been explained to them.

\section{Methods}

Each woman was given instruction in the correct procedure for collecting an accurate 24-hour urine sample. The samples were received by the laboratory within a few hours of dispatch. Collections were made in large polyethylene bags placed in tared 3-1. polyethvlene-capped jars. The volumes were estimated from the weight of the sample by assuming a specific gravity of 1000 . Errors of estimation by this procedure were found to be negligible.

Aliquots were stored in glass jars either at $4^{\circ} \mathrm{C}$ if the analyses were to be performed within seven days of receipt or at $-20^{\circ} \mathrm{C}$ if longer. No preservatives were used. 11-Deoxy-17oxosteroids (11-DOS) were measured by the Portsmouth variant described by Thomas et al. (1969). 17-Oxogenic steroids (17-OGS) were measured by Metcalf's (1963) method. With these methods a negative alternative discriminating function (11-DOS/17-OGS) has a value below 0:11.

Since a number of the samples, especially in those patients with hepatic disease, contained bile pigments which are excreted as glucuronosides and so may compete with the steroid glucuronosides during enzymic hydrolysis, the effects of adding conjugated bilirubin (obtained from gall bladders at necropsy) to urine was studied. No significant differences in steroid measurement were found whether or not bile was added to the samples.

\section{Results}

The mean steroid excretion values obtained from each group together with the variance and the significance of the deviations from normal levels are shown in table I.

TABLE I-Mean Daily Urinary Steroid Excretion in Each Study Group

\begin{tabular}{|c|c|c|c|c|c|c|c|}
\hline \multirow{2}{*}{ Subjects } & \multirow{2}{*}{$\begin{array}{c}\text { No. } \\
\text { of } \\
\text { Samples }\end{array}$} & \multicolumn{3}{|c|}{$\begin{array}{l}\text { 17-OGS } \\
\text { (mg/day) }\end{array}$} & \multicolumn{3}{|c|}{$\begin{array}{l}\text { 11-DOS } \\
\text { (mg/day) }\end{array}$} \\
\hline & & Mean & S.D. & $\mathbf{P}$ & Mean & S.D. & $\mathbf{P}$ \\
\hline $\begin{array}{ll}\text { Normal } & \text { Chronic debility } \\
\text { Weight watchers: }\end{array}$ & $\begin{array}{l}48 \\
12\end{array}$ & $\begin{array}{r}11 \cdot 2 \\
8.3\end{array}$ & $\begin{array}{l}2 \cdot 9 \\
2 \cdot 8\end{array}$ & $<0.05$ & $\begin{array}{l}5 \cdot 0 \\
2 \cdot 7\end{array}$ & $\begin{array}{l}2 \cdot 7 \\
2 \cdot 0\end{array}$ & $<0.01$ \\
\hline $\begin{array}{c}\text { 1st sample } \\
\text { 2nd sample } \\
\text { Varicose veins: }\end{array}$ & $\begin{array}{l}10 \\
10\end{array}$ & $\begin{array}{l}13.3 \\
11.0\end{array}$ & $\begin{array}{l}5 \cdot 2 \\
3 \cdot 4\end{array}$ & $\begin{array}{l}<0.05 \\
\text { N.S. }\end{array}$ & $\begin{array}{l}5 \cdot 3 \\
3 \cdot 7\end{array}$ & $\begin{array}{l}2 \cdot 6 \\
2 \cdot 2\end{array}$ & $\begin{array}{l}\text { N.S. } \\
<0.05\end{array}$ \\
\hline $\begin{array}{l}\text { Preoperative } \\
\text { 1st postoperative day } \\
\text { 2nd postoperative day } \\
\text { Hepatic disease: }\end{array}$ & $\begin{array}{l}20 \\
16 \\
14\end{array}$ & $\begin{array}{l}12 \cdot 1 \\
19 \cdot 3 \\
13 \cdot 7\end{array}$ & $\begin{array}{r}3.4 \\
13.1 \\
3.9\end{array}$ & $\begin{array}{l}\text { N.S. } \\
<0.001 \\
<0.05\end{array}$ & $\begin{array}{l}3 \cdot 8 \\
4 \cdot 1 \\
2 \cdot 9\end{array}$ & $\begin{array}{l}1 \cdot 7 \\
3 \cdot 3 \\
1 \cdot 5\end{array}$ & $\begin{array}{l}\text { N.S. } \\
\text { N.S. } \\
<0.01\end{array}$ \\
\hline $\begin{array}{ccc}\text { Mildly ill } & \ldots & \ldots \\
\text { Ill } & \ldots & \ldots\end{array}$ & $\begin{array}{l}31 \\
28\end{array}$ & $\begin{array}{l}14 \cdot 4 \\
13 \cdot 5\end{array}$ & $\begin{array}{l}7 \cdot 0 \\
7 \cdot 6\end{array}$ & $\begin{array}{l}<0.05 \\
<0.05\end{array}$ & $\begin{array}{l}3 \cdot 1 \\
1 \cdot 2\end{array}$ & $\begin{array}{l}2 \cdot 3 \\
0 \cdot 8\end{array}$ & $\begin{array}{l}<0.05 \\
<0.001\end{array}$ \\
\hline $\begin{array}{cc}\text { Non-mammary cancer: } \\
\text { Localized } & \ldots \\
\text { Advanced } . . & \ldots\end{array}$ & $\begin{array}{r}29 \\
8\end{array}$ & \begin{tabular}{|l|}
$12 \cdot 1$ \\
$10 \cdot 4$
\end{tabular} & $\begin{array}{l}5 \cdot 2 \\
4 \cdot 2\end{array}$ & $\begin{array}{l}\text { N.S. } \\
\text { N.S. }\end{array}$ & $\begin{array}{l}3.7 \\
1.4\end{array}$ & $\begin{array}{l}2.5 \\
1.5\end{array}$ & $\begin{array}{r}<0.05 \\
<0.001\end{array}$ \\
\hline
\end{tabular}

N.S. $=$ Not significant $(P>0.05)$.

Patients with chronic debility showed a reduction of both corticosteroid (17-OGS) and adrenal androgen (11-DOS) excretion, the former levels being less significant than the latter.

The "weight watchers," who could not really be considered to be obese, showed a slight increase of corticosteroid excretion with normal androgens. The former finding is well known in obese subjects. After a month of their self-imposed regimen the corticosteroid excretion had returned to normal, but the androgens had reduced significantly.

On the day of admission to hospital, the varicose vein patients were normal, and as expected the corticosteroid excretion rose markedly on the first day after operation and began to return to normal on the second day. However, androgen excretion was significantly reduced by the second postoperative day.

Of the women with hepatic disease corticosteroids were increased whether they were judged to be "mildly ill" or "ill," but androgen excretion was depressed, and markedly so in those judged to be "ill."

The women with non-mammary cancer did not show any change in corticosteroid excretion whether the disease was localized or advanced, but androgen excretion was significantly reduced-most severely in those with the advanced disease.

The effects of these results on the alternative discriminating functions are shown in table II. In the chronic debility group there was a fall in the value, but none had negative functions.

TABLE II-Results of Tests for Alternative Discriminating Function in Each Study Group

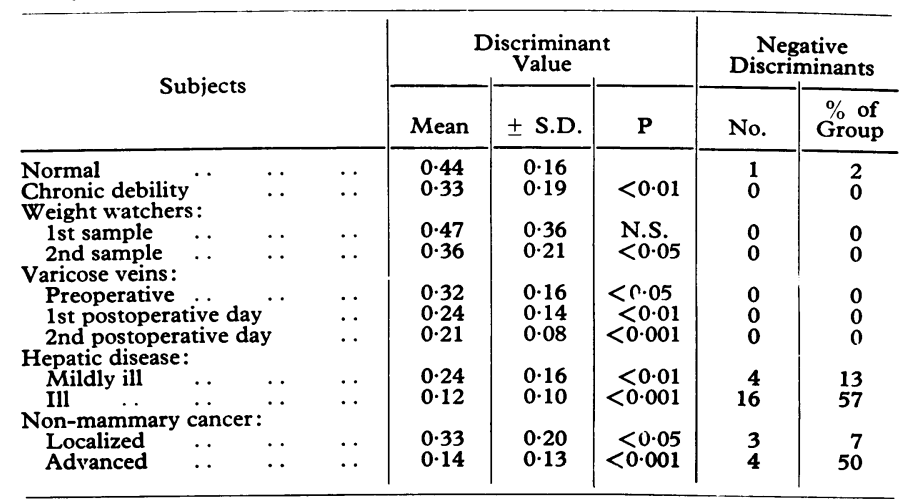

N.S. = Not significant $(\mathbf{P}<0.05)$. 
TABLE III-Observations During Remission of Acute Infective Hepatitis

\begin{tabular}{|c|c|c|c|c|c|c|c|c|c|c|c|c|}
\hline & & & \multirow{2}{*}{$\begin{array}{c}\text { No. } \\
\text { of } \\
\text { Observations }\end{array}$} & \multicolumn{3}{|c|}{ 17-OGS (mg/day) } & \multicolumn{3}{|c|}{ 11-DOS (mg/day) } & \multicolumn{3}{|c|}{ Discriminant Value } \\
\hline & & & & Mean & S.D. & $P$ & Mean & S.D. & $\mathbf{P}$ & Mean & S.D. & $\mathbf{P}$ \\
\hline $\begin{array}{l}\text { Normal } \\
\text { 1st sample } \\
\text { 2nd sample } \\
\text { 3rd sample }\end{array}$ & $\begin{array}{l}. \\
\ldots \\
\ldots\end{array}$ & $\begin{array}{l}. \\
\cdots \\
\cdots \\
\cdots\end{array}$ & $\begin{array}{r}48 \\
26 \\
22 \\
8\end{array}$ & $\begin{array}{l}11 \cdot 2 \\
14 \cdot 1 \\
13 \cdot 8 \\
11 \cdot 1\end{array}$ & $\begin{array}{l}3.9 \\
7.3 \\
4 \cdot 6 \\
3.5\end{array}$ & $\begin{array}{l}<0.05 \\
<0.05 \\
\text { N.S. }\end{array}$ & $\begin{array}{l}5 \cdot 0 \\
2 \cdot 1 \\
2 \cdot 6 \\
3 \cdot 3\end{array}$ & $\begin{array}{l}2 \cdot 7 \\
2 \cdot 0 \\
2 \cdot 5 \\
2 \cdot 6\end{array}$ & $\begin{array}{l}<0.001 \\
<0.01 \\
\text { N.S. }\end{array}$ & $\begin{array}{l}0 \cdot 44 \\
0 \cdot 17 \\
0 \cdot 17 \\
0 \cdot 27\end{array}$ & $\begin{array}{l}0 \cdot 16 \\
0.13 \\
0 \cdot 18 \\
0 \cdot 16\end{array}$ & $\begin{array}{l}<0.001 \\
<0.001 \\
<0.05\end{array}$ \\
\hline
\end{tabular}

N.S. $=$ Not significant $(P>0.05)$.

The "weight watchers" showed a slight fall in value after one month's trial of the regimen. The varicose vein patients showed a progressive fall in the value over the period of study. On the first postoperative day this was due to a rise in the denominator of the ratio, whereas on the second day, when the change was most pronounced, it was due principally to a fall in the numerator of the ratio-the androgenic fraction.

All the women with hepatic disease showed falls in the value, which were most significant in the "ill" group $(57 \%$ had negative discriminants). Even in the "mildly ill" group $13 \%$ had negative discriminants.

Finally, in the non-mammary cancer group the localized disease showed $7 \%$ with negative discriminants whereas half of those with advanced disease had negative values.

The changes in the three factors in the patients with acute infective hepatitis as they progressed to recovery are shown in table III. It is clear that corticosteroid excretion is less disturbed and returns to normal more quickly than the androgen excretion, and this is reflected in the discriminant values.

The results confirm our previous report (Miller and Durant, 1968) that it is depressed androgen excretion more than excess corticosteroid excretion that leads to falls in the discriminant value.

\section{Discussion}

Whatever the reason for the presence of a negative urinary discriminant function, there seems little doubt that if it is present in women with advanced breast cancer there is a poorer chance of responding satisfactorily to endocrine organ ablation than if the fraction had been positive. Hayward and Bulbrook (1968) studied 151 patients with advanced breast cancer who were treated by adrenalectomy or hypophysectomy. Of those with a positive discriminant function $35 \%$ responded favourably while $41 \%$ did not. Yet of those with negative discriminants only $16 \%$ responded favourably and as many as $60 \%$ did not. They also found that nearly a third of their patients could be placed in a category which had only a $5 \%$ chance of a satisfactory response. All those in this category had negative discriminants. They had either presented for the first time with the disease already in the advanced stage and were within six years of having reached their menopause, or they had developed their first recurrence of the disease within two years of mastectomy-that is, a "free interval" of less than two years. The greatest value of the discriminant function may well be in the recognition of this group of poor responders.

Though Nabarro (1960) had suggested that the stress of illness associated with advanced breast cancer would produce a negative discriminant because of a consequent rise in conticosteroid excretion, we found in our series of women with breast cancer (Miller and Durant, 1968) that the presence of a negative discriminant, whether the disease was advanced or localized, was associated with a fall of androgen excretion rather than with any rise of corticosteroid excretion.

In our hands, simulated acute stress by the administration of large doses of corticotrophin (ACTH) produced a rise of corticosteroid excretion and a rise of androgen excretion. Both steroid groups are derived from a common intermediate pre- cursor-17 $\alpha-\mathrm{OH}$-pregnenolone, secreted in response to ACTH stimulation (Cameron, 1969). The naturally induced acute stress of the surgical operation for varicose veins produced only a $50 \%$ rise in corticosteroid excretion on the first postoperative day, levels returning to normal by the second day. Androgen excretion, however, had begun to fall by the first postoperative day and had fallen significantly by the second day. The factor of admission to hospital caused no significant changes.

Perhaps the effects of natural stress are not confined solely to the results of ACTH secretion or, alternatively, corticosteroid secretion is maintained at the expense of androgen secretion.

The result of mild dietary restriction was a reduction in androgen excretion. In states of chronic debility there was a significant reduction in androgen excretion and a less significant fall in corticosteroid excretion. Negative discriminants were not found in any of these three groups of subjects.

The most striking of our results were found in the patients with severe hepatic disease and in those with advanced nonmammary cancer. The changes once again were largely confined to an appreciable reduction in androgen excretion, sufficient to product a high proportion of negative discriminants. In the patients with hepatic disease, as the condition progressed to recovery so the androgen excretion returned to normal and the discriminant value rose (table III).

The question arises whether in these latter two groups the changes of androgen excretion are the result of interference with hepatic metabolism of adrenocortical steroids rather than a function of altered adrenocortical secretion. This may also explain the differences found between simulated and natural acute stress.

Further evidence for the non-specificity of the changes seen in breast cancer is furnished by Rao (1970) in his study of lung cancer in man. He found that there was a correlation between poor prognosis after lung resection with subnormal androgen and raised conticosteroid excretion, and the inoperable cases survived longer if their steroid patterns were normal than if they were disturbed.

We conclude that the urinary steroid changes seen in advanced breast cancer are a measure of the general metabolic systemic disturbance, or degree of "illness" caused by the disease, as was suggested by Nabarro (1960) and by us (Miller and Durant, 1969), though different reasons were given.

Our thanks are due to the women volunteers for their ready co-operation, and the doctors of the Portsmouth Group of Hospitals for allowing us to study patients under their care. We are indebted to the Wessex Regional Hospital Board, Tenovus of Wales, and the Catholic Marriage Advisory Council for generous research grants. We are also grateful to Mr. Morse of the Portsmouth Polytechnic for the statistical work carried out on our behalf.

The work described in this paper formed part of the thesis submitted by J.A.D. for the degree of Ph.D. in the University of London. H.M. acted as supervisor.

\section{References}

Bulbrook, R. D., and Hayward, J. L. (1967). Lancet, 1, 519. 
Bulbrook, R. D., Greenwood, F. C., and Hayward, J. L. (1960). Lancet, 1,1154 .

Bulbrook, R. D., Hayward, J. L., Spicer, C. C., and Thomas, B. S. (1962). Lancet, 2, 1238 .

Cameron, E. H. D. (1969). The Human Adrenal Gland and its Relation to Breast Cancer, ed. K. Griffiths, and E. H. D. Cameron, p. 47. Cardiff, Alpha Omega Alpha.

Hayward, J. L., and Bulbrook, R. D. (1968). Prognostic Factors in Breast Cancer, ed. A. P. M. Forrest, and P. B. Kunkler, p. 383. Edinburgh,
Livingstone.
Metcalfe, M. G. (1963). Fournal of Endocrinology, 26, 415.

Miller, H., Durant, J. A., Jacobs, A. G., and Allison, J. F. (1967). British Medical fournal, $1,147$.

Miller, H., and Durant, J. A. (1968). Clinical Biochemistry, 1, 286.

Miller, H., and Durant, J. A. (1969). Lancet, 1, 1313.

Nabarro, J. D. N. (1960). Lancet, 1, 1293.

Rao, I G. S (1970). Lancet, 2 , 141 .

Thomas, B. S., Bulbrook, R. D, and Hayward, J. L (1967). British Medical fournal, 2, 523.

Thomas, B. S., Bulbrook, R. D., Durant, J. A., Miller, H., and Ross, D. M. (1969). Clinical Biochemistry, 2, 311.

\title{
Malignant Carcinoid Tumour with Gangrene of the Small Intestine
}

\author{
IAIN M. MURRAY-LYON, M. O. RAKE, A. K. MARSHALL, ROGER WILLIAMS
}

British Medical fournal, 1973, 4, 770-771

\begin{abstract}
Summary
Four patients with a malignant carcinoid tumour of the small bowel (three had the carcinoid syndrome) developed gangrene of the small intestine. Attention is drawn to this seldom recognized complication, as early surgery may be life saving.
\end{abstract}

\section{Introduction}

Abdominal pain commonly occurs in the carcinoid syndrome and is usually secondary to the disturbance of intestinal motility. Intestinal obstruction either due to the tumour itself or to kinking of the bowel caused by the commonly associated fibrous reaction may also occur (McNeal, 1971; GrahamSmith, 1972). Yet another cause of abdominal pain, but one not well known, is gangrene of the small intestine. In this paper we report on four patients in whom we have seen this develop. Recognition is vital since a fatal outcome is inevitable unless early surgery is carried out.

\section{Case Histories}

Case 1.-This 70-year-old man started to have severe episodes of flushing and diarrhoea in February 1969. Urinary 5-hydroxyindole acetic acid (5-HIAA) excretion was raised $(54-70 \mathrm{mg} / 24 \mathrm{hr}$ ) as was the blood 5-hydroxytryptamine $(5-\mathrm{HT}$ ) at $0.83 \mu \mathrm{g} / \mathrm{ml}$ (normal $0.037-0.28 \mu \mathrm{g} / \mathrm{ml}$ ). Liver biopsy showed metastatic carcinoid tissue. The primary site appeared to be a stenosing lesion in the mid ileum. The latter was bypassed by a side-to-side anastomosis, the hepatic metastases being treated by local perfusion of fluorouracil followed by ligation of the hepatic artery (case 6, MurrayLyon et al., 1970). For a year he was much improved but then the diarrhoea and flushing again became troublesome, the urinary 5-HIAA excretion having increased again to preoperative levels. In June 1970 he was readmitted to hospital with bronchopneumonia but then developed abdominal pain with signs of peritonitis and he died three days later. At necropsy (Dr. I. M. Magrath) there was a

\footnotetext{
Liver Unit and Department of Morbid Anatomy, King's College Hospital, London SE5 8RX, and Guy's Hospital, London SE1 9RT IAIN M. MURRAY-LYON, M.B., M.R.C.P., Senior Registrar in General Medicine

M. O. RAKE, M.B., M.R.C.P., Research Fellow (Present appointment: Consultant Physician, Kent and Canterbury Hospital, Canterbury) A. K. MARSHALL, M.B., M.R.C.PATH., Senior Registrar ROGER WILLIAMS, M.D., F.R.C.P., Physician, and Director of Liver Unit
}

mass of carcinoid tumour in the mid jejunum and the adjoining mesentery incorporating several large lymph nodes. Through this passed a branch of the superior mesenteric artery supplying a $1-m$ length of mid-ileum which had become gangrenous. Histological examination of the part of the artery passing through the tumour mass showed dense elastic tissue in both the intima and adventitia (see photograph). The lumen appeared narrowed but no thrombus was present. Similar changes were present in the accompanying vein.

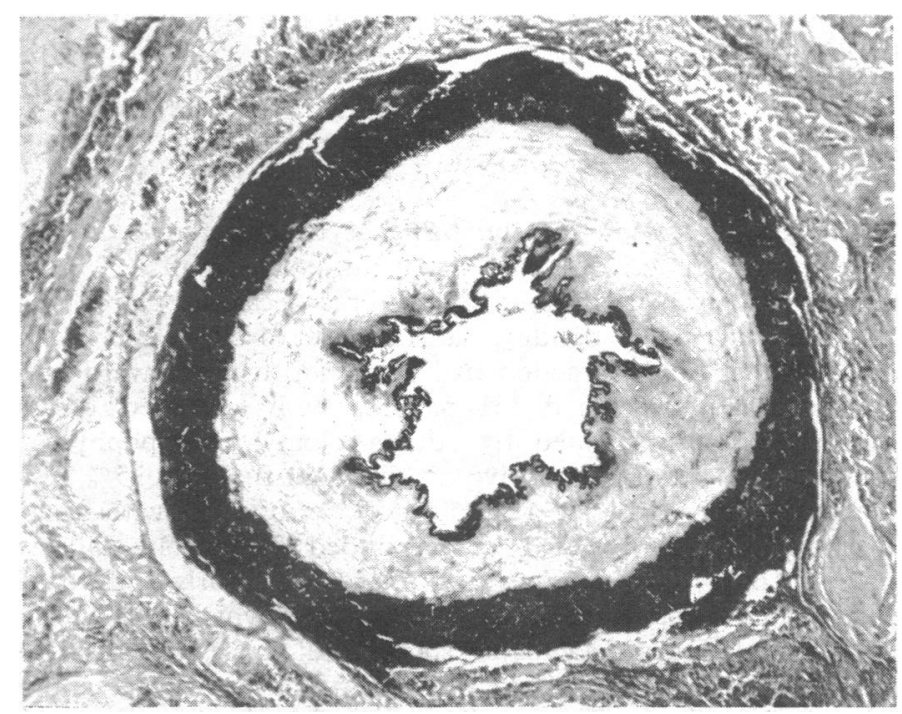

Mesenteric artery from case 1 showing elastic sclerosis of the adventitia. (Elastic van Gieson. x 30.)

Case 2.-A 38-year-old woman was found to have a carcino:d tumour of the terminal ileum with multiple hepatic and peritoneal metastases in January 1969. A bypass operation was performed and she remained reasonably well over the next two years, though increasingly troubled by attacks of flushing and diarrho:a. When investigated again in October 1971 she had gross hepatomegaly, and both urinary 5-HIAA $(240-550 \mathrm{mg} / 24 \mathrm{hr})$ and blood 5-HT $(1.88 \mu \mathrm{g} / 100)$ were greatly raised. Some control of her symptoms was achieved by codeine phosphate, but after a few weeks she was readmitted with a five-day history of increasing abdominal pain and diarrhoea. Examination showed generalized abdominal tenderness, and a few days later signs of peritonism appeared and plain films of the abdomen showed signs of small bowel obstruction. Peritoneal tap produced faeculent fluid. Her general condition deteriorated rapidly and she died six days after admission. At necropsy there was purulent peritonitis. Loops of ileum were 